\title{
Testicular Mixed Choriocarcinoma and Teratoma
}

National Cancer Institute

\section{Source}

National Cancer Institute. Testicular Mixed Choriocarcinoma and Teratoma. NCI

Thesaurus. Code C6349.

A malignant mixed germ cell tumor arising from the testis. It is characterized by the presence of a teratomatous component and malignant syncytiotrophoblastic cells. 